\title{
Peningkatan Potensi Anggota KWT dalam Pemanfaatan Pekarangan untuk Tanaman Obat dan Kosmetika Menggunakan Metode Tanam Vertikal di Desa Cibiru Wetan, Kabupaten Bandung
}

\author{
Widhya Aligita ${ }^{1}$, Fauzan Zein Muttaqin², Soni Muhsinin², Ellin Febrina ${ }^{3}$, \\ Aiyi Asnawi ${ }^{4}$ \\ 1,2 Universitas Bhakti Kencana, ${ }^{3}$ Universitas Padjadjaran, ${ }^{4}$ Institut Teknologi Bandung
}

\begin{abstract}
Article History ABSTRACT
Received 07.08.2019

Received in revised form 22.10.2019

Accepted 03.12.2019

Available online 16.12.2019

POTENTIAL DEVELOPMENT OF WOMAN FARMING GROUP IN THE UTILIZATION OF THE YARD FOR DRUG AND COSMETICS PLANTS USING VERTICAL GARDEN METHOD IN CIBIRU WETAN VILLAGE, BANDUNG REGENCY. The village of Cibiru Wetan is largely a rice field and swidden area with hilly contours and insufficient water availability. One of the utilization of fields with a lack of water is by growing plants that require minimal water, including medicinal plants and cosmetics. The initiation of this activity has a high prospect of success due to the high initiative and participation of the population in the form of women's farmer groups and the family welfare team as evidenced by the many achievements, awards, and skills gained by the Cibiru Wetan Village through the participation of its citizens. Therefore, the purpose of the project activity was socialization and practice at women's farmer group of Cibiru Wetan Village through the use of medicinal plants and cosmetics with simple appropriate technology through vertical gardening. The method of implementation used in the training program for planting medicinal plants was divided two stage, that was providing information about family medicinal plants ranging from understanding to the benefits of the plants, and the last step was explaining or training and direct practice of planting medicinal plants and cosmetics using vertical planting. The results showed a positive understanding of the two groups of women's farmer group I and II and the family welfare team, both for the stage of socialization and counseling as well as for the practice phase of planting medicinal plants and cosmetics vertically. The conclusion was the use of medicinal plants and cosmetics could increase the understanding of the target group and the compost produced by residents could be utilized through this activity.
\end{abstract}

KEYWORDS: Cosmetic, Herb, KWT, Vertical Garden, Yard.

This is an open access article distributed under the terms of the Creative Commons Attribution 4.0 International License, which permits unrestricted use, distribution, and reproduction in any medium, provided the original work is properly cited. (c) 2019 Widhya Aligita, Fauzan Zein Muttaqin, Soni Muhsinin, Ellin Febrina, Aiyi Asnawi.

4 Corresponding author: Sekolah Farmasi, Institut Teknologi Bandung, Jl. Ganesha 10 Bandung, 40132, Indonesia. Email: aiyiasnawi@fa.itb.ac.id 


\section{PENDAHULUAN}

Halaman atau pekarangan rumah biasanya memiliki luas lahan terbatas. Namun masih belum dimanfaatan dengan optimal baik sebagai ruang terbuka maupun sebagai media taman. Khususnya untuk media taman tentunya selain keasrian juga tak kalah penting untuk memanfaatkannya sebagai media taman yang berfungsi sebagai penghasil tanaman obat yang lebih dikenal dengan Taman Obat Keluarga (TOGA). Kata "Taman" menunjukkan terhadap usaha untuk meningkatkan nilai estetika tanaman - dalam hal ini tanaman obat-dengan adanya pengaturan yang sesuai dengan potensi lahan dan enak dipandang mata. Sedangkan kata "Keluarga" menunjukkan taman ini berfungsi untuk menjaga kesehatan seluruh anggota keluarga dan dibuat di lingkungan keluarga, yaitu di pekarangan rumah, sekolah atau kantor.

Jenis tanaman obat sebaiknya dipilih yang penting dan bermanfaat untuk keperluan menjaga kesehatan keluarga sehari-hari. Selain itu, dipilih jenis tanaman yang mudah dibudidayakan dan tidak menyita tempat karena ukuran tajuk yang besar. Tanaman obat dan kosmetika juga sekarang mulai dibudidayakan untuk bisnis yang menghasilkan keuntungan cukup lumayan besar, karena tanaman obat dan kosmetika dapat diolah menjadi berbagai produk yang berkhasiat bagi kesehatan sebagai pengganti obat.

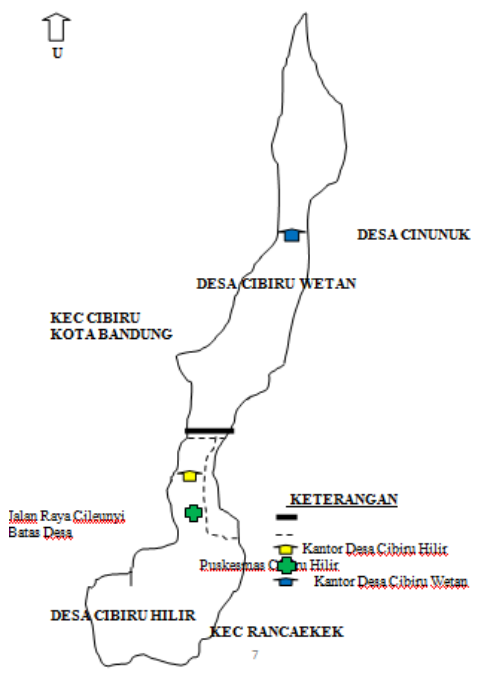

Gambar 1. Peta Desa Cibiru Wetan, Kab. Bandung, Jawa Barat

Cibiru Wetan adalah salah satu desa yang tergabung dalam Kecamatan Cileunyi, Kabupaten Bandung, Provinsi Jawa Barat. Secara geografis desa ini berada di kawasan Gunung Manglayang, dengan batas-batas: sebelah utara berbatasan dengan Gunung Manglayang itu sendiri; sebelah selatan berbatasan dengan Desa Cibiru Kulon; sebelah barat berbatasan dengan Desa Cibiru Wetan dan Desa Desa Cilengkrang; dan sebelah timur berbatasan dengan Desa Cimekar. Desa ini tidak hanya berada di kaki tapi juga di lereng gunung, sehingga wilayahnya tidak hanya berupa dataran rendah semata, tetapi juga dataran tinggi (berbukit-bukit) yang mendominasinya.

Secara keseluruhan, luas desa ini mencapai $295 \mathrm{Ha}$, dengan rincian: perumahan penduduk (71,5 Ha atau 24,24\%), sawah (2 Ha atau 0,67\%), tegalan/ladang (153,5 Ha atau $45,93 \%)$, empang/kolam (1,5 Ha atau $0,5 \%)$, kas desa (12,5 Ha atau $4,24 \%$ ), lapangan ( $3 \mathrm{Ha}$ atau $1,01 \%)$, perkantoran pemerintah $(2,05 \mathrm{Ha}$ atau $0,69 \%)$, dan lain-lain4) $(48,95 \mathrm{Ha}$ atau 16,59\%) (Halimah, 2007). Pekarangan rumah penduduk sebesar $24,24 \%$ dari luas total 
lahan Desa Cibiru Wetan umumya hanya dimanfaatkan untuk menanam tanaman hias hanya untuk mempercantik rumahnya. Namun akhir-akhir ini walaupun telah meningkat dalam penggunaan obat herbal tetapi gaung dari TOGA tidak terlalu terasa. Salah satu faktor penyebabnya adalah kurangnya pengembangan dan sosialisasi TOGA (Kasim \& Segara, 2012; Muttaqin et al, 2018).

Dengan adanya lahan perkarangan warga Desa Cibiru Wetan yang idle/tak diberdayakan sebesar $24,24 \%$ maka dapat diberdayakan tidak hanya sebagai tanam yang asri juga sebagai fungsi penambahan sumber pemasukan bagi rumah tangga. Disisi lain, pengurangan terhadap penggunaan obat yang diproduksi secara industri. Dimana sebagian obat dari TOGA mampu memberi solusi untuk penyembuhan penyakit umum di masyarakat.

Dari wawancara dengan kepala desa Cibiru Wetan mengatakan bahwa mereka telah mendapatkan pelatihan pembuatan kompos beserta dengan sarana pembuatan kompos dari kotoran ternak sapi dengan metode Takakura (Muhsinin, Dinata, Andriansyah, \& Asnawi, 2019), tetapi kendalanya jumlah kompos yang dihasilkan tidak cukup banyak untuk dijual, disamping masih belum seragam kualitas produk kompos yang dihasilkan. Oleh karenanya kepala desa sangat berharap ditemukan alternatif penyaluran kompos hasil produksi dari rumah tangga.

Menanggapi keluhan dan potensi yang dapat dikembangkan maka tujuan dari kegiatan ini adalah memanfaatkan dan mengembangkan tanaman obat dan kosmetika di Desa Cibiru Wetan sebagai sendi pendapatan baru bagi kelompok sasaran. Desa Cibiru Wetan dipilih karena partisipasi aktif dari Ibu PKK dan Kelompok Wanita Tani (KWT) dalam berbagai kegiatan desa (Muttaqin et al, 2018; Muhsinin, Dinata, Andriansyah, \& Asnawi, 2019). Dengan adanya transfer teknologi untuk anggota kelompok sasaran dalam pemanfaatan tanaman obat dan kosmetika di perkarangan rumah masyarakat untuk akan dapat mengimplementasikan pengetahuan tentang pembuatan kompos untuk digunakan sebagai pupuk untuk tanaman obat dan kosmetika.

\section{METODE PELAKSANAAN}

Kelompok yang menjadi sasaran kegiatan ini adalah 2 Kelompok Wanita Tani (KWT) Desa Cibiru Wetan. Jumlah orang secara keseluruhan adalah 10 orang yang dibagi menjadi dua kelompok yaitu KWT I (KWT dalam area Desa Cibiru bagian atas) dan KWT II (KWT dalam area Desa Cibiru bagian bawah). Rata-rata pendidikan anggota kelompok sasaran adalah SMP. Pada umumnya ibu-ibu ini bekerja sebagai petani $(80 \%)$, sisanya mengurus rumah tangga dan dagang.

Metode pelaksanaan yang digunakan dalam program pelatihan penanaman tanaman obat ini dibagi menjadi beberapa tahapan. Tahapan pertama adalah memberikan penyuluhan materi tentang tanaman obat keluarga mulai dari pengertian hingga manfaat dari tanaman tersebut, tahapan kedua adalah memberikan penjelasan atau pelatihan menanam tanaman obat keluarga terutama memperkenalkan metode penanaman secara vertikal, dan tahapan ketiga adalah melakukan praktek secara langsung dalam menanam tanaman obat tersebut.

Kegiatan dilaksanakan per minggu untuk tiap topik/tahapan kegiatan. Kegiatan praktek difokuskan di lahan percontohan dan Aula Kantor Desa Cibiru Wetan, 
Kabupaten Bandung, Jawa Barat, serta hasil praktek diterapkan langsung disetiap rumah anggota Ibu PKK dan KWT yang terlibat. Diharapkan setiap rumah di Cibiru Wetan akan mampu memanfaatkan halaman rumah sebagai tanaman obat dan kosmetika.

\section{HASIL DAN PEMBAHASAN}

Indonesia merupakan negara yang kaya, dan kawasan hutannya merupakan sumber keragaman hayati. dan Indonesia sudah di kenal dengan kekayaan rempah-rempahnya dari berbagai jenis tanaman. Sejak dulu sudah banyak digunakan oleh masyarakat untuk mengatasi berbagai penyakit baik yang ringan maupun kronis. Tanaman Herbal dikenal juga dengan tanaman obat. Tanaman obat herbal ini memiliki banyak kelebihan jika dibandingkan dengan tanaman-tanaman lain. kelebihan tanaman obat herbal ini yaitu bermanfaat untuk tubuh dalam meningkatkan daya tahan dan mencegah serta mengobati tubuh dari berbagai penyakit. Selain mengingat efek sampingnya yang kecil tapi juga khasiatnya yang besar bila dibanding obat berbahan kimia. Dilansir Nationalgeographic, bahwa hutan Indonesia menjadi habitat bagi 30.000 dari total sekitar 40.000 jenis tumbuhtumbuhan obat yang telah dikenal di dunia. Jumlah tersebut mewakili 90 persen dari tumbuhan obat yang terdapat di wilayah Asia (Rahmansyah, 2017).

Vertical garden atau taman vertikal merupakan sebuah konsep taman tegak atau vertikal dengan megatur tanaman dan elemen taman lainnya sedemikian rupa pada sebuah bidang tegak. Konsep taman vertikal merupakan sebuah upaya untuk menghijaukan sebuah tempat yang terbatas dimana tempat tersebut tidak memungkinkan untuk dibuat taman horizontal. Taman vertikal mulai banyak dikembangkan di Indonesia, terutama di kota-kota besar. Dengan konsep vertikal garden kita bisa memanfaatkan tembok rumah, dinding atau pagar dan bidang tegak lainnya sebagai area taman. Jika anda tinggal di kota dan tidak memiliki lahan yang cukup untuk membuat taman, konsep vertikal garden bisa menjadi pilihan untuk menghijaukan dan mempercantik rumah anda. Konsep ini bisa diterapkan pada berbagai bidang tegak seperti tembok rumah, gedung perkantoran, cartport atau pagar baik indoor maupun outdoor. Beberapa fungsi dan manfaat taman vertikal adalah (Azzamy, 2016):

1) Sebagai seni dinding untuk memperindah dan mempercantik sebuah tempat,

2) Sebagai pembersih udara (filter udara) untuk mengurangi kadar polusi pada sebuah ruangan atau wilayah,

3) Sebagai penyejuk ruangan atau wilayah,

4) Dengan desain dan jenis tanaman yang unik taman vertikal dapat menambah kesan artisitik pada sebuah bangunan,

5) Mengurangi penyerapan sinar matahari oleh dinding sehingga sebuah ruangan atau wilayah menjadi lebih sejuk,

6) Dengan adanya taman vertikal ketersediaan oksigen menjadi lebih banyak dan kesehatan penduduk kota meningkat.

Berdasarkan cara pembuatannya pupuk secara garis besar dapat dibedakan menjadi dua jenis pupuk yaitu pupuk anorganik/kimia dan pupuk organik (Suwahyono, 2011). Pupuk anorganik/kimia pada dasarnya merupakan buatan pabrik dengan jenis dan kadar unsur hara tertentu, misalnya pupuk urea, SP-36, dan KCL. Sementara pupuk organik 
merupakan pupuk yang berbasiskan bahan alam sebagai bahan baku utama penyusunnya, misalnya pupuk kompos, pupuk hijau dan pupuk organik bokashi (Utomo, 2007). Sedangkan mengatakan kompos merupakan hasil akhir suatu proses fermentasi tumpukan sampah, serasah tanaman ataupun bangkai binatang. Ciri kompos yang baik adalah berwarna coklat, berstruktur remah, berkonsistensi gembur dan berbau daun lapuk (Yuliarti, 2009).

Pelaksanaan kegiatan pengabdian kepada masyarakat ini dilakukan dalam beberapa tahap dengan target tiap tahapan yang berbeda-beda tetapi berkesinambungan. Kegiatan utama berupa sosialisasi tentang tanaman obat dan kosmetika dan pemanfaatan lahan, dan praktek budidaya tanaman obat dan kosmetika. Semua kelompok sasaran Ibu PKK dan KWT dilakukan treatment yang sama untuk melihat pengaruh terhadap hasil treatment dari metode yang digunakan.

\section{Sosialisasi dan Penyuluhan Tanaman Obat dan Kosmetika}

Kegiatan sosialisasi ini yaitu pemberian materi tentang pengertian tanaman obat keluarga, manfaat dari tanaman, dan jenis produk simplisia herbal dilakukan selama dua hari. Penyuluhan hari pertama untuk KWT I dan KWT II dan hari kedua untuk Ibu PKK. Tujuan dari tahapan ini adalah agar semua kelompok sasaran mencintai lingkungan dan gerakan menanam. Kegiatan ini berupa penyuluhan, diskusi dan tanya jawab. Hasil kegiatan menunjukkan peningkatan pemahaman dari kelompok sasaran tentang materi yang diberikan.
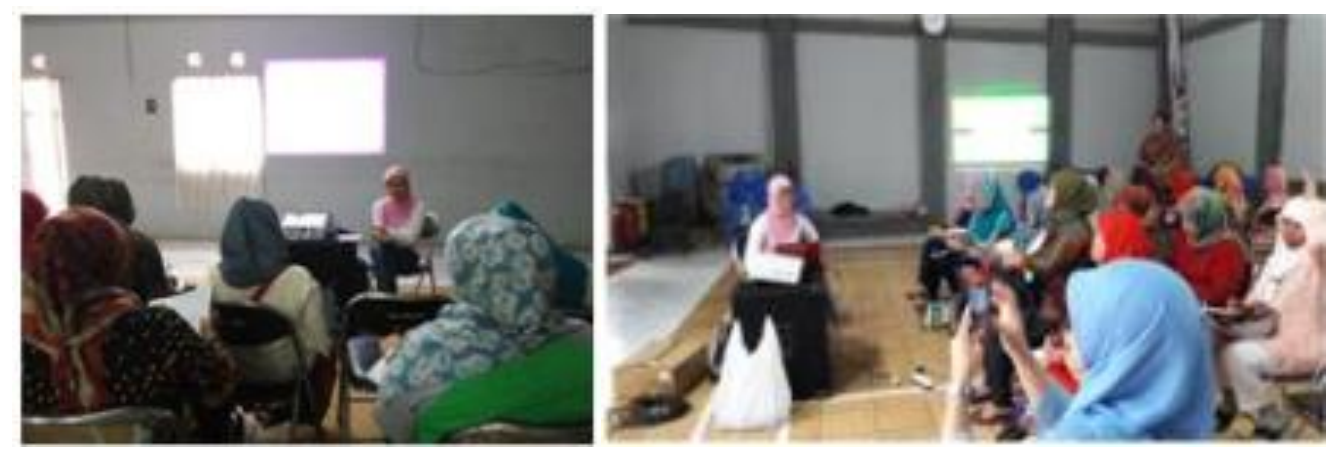

Gambar 2. Kegiatan Sosialisasi dan Penyuluhan Tanaman Obat dan Kosmetika

\section{Budidaya Tanaman Obat dan Kosmetika}

Pelatihan ini dimulai dengan pemaparan tentang teknik budidaya tanaman obat dan kosmetika. Salah satu metode yang diperkenalkan adalah penanaman secara vertikal. Dengan berkebun secara vertical, kita harus mempertimbangkan ruang tanah yang akan kita gunakan untuk menanam, karena hal ini tentu akan berpengaruh pada tingkat kesuburan dan kondisi tanaman yang akan kita tanam (Byaz, 2013).

Untuk menjaga kesuburan tanah, maka kompos hasil olahan warga dengan metode Takakura (Soni, dkk, 2019) dapat diimplementasikan, sehingga kendala pemanfaatan kompos tersebut dapat dipecahkan. Kegiatan ini berupa penyuluhan, praktek, diskusi, dan tanya jawab. Hasil kegiatan menunjukkan peningkatan pemahaman dari kelompok sasaran tentang materi yang diberikan. 


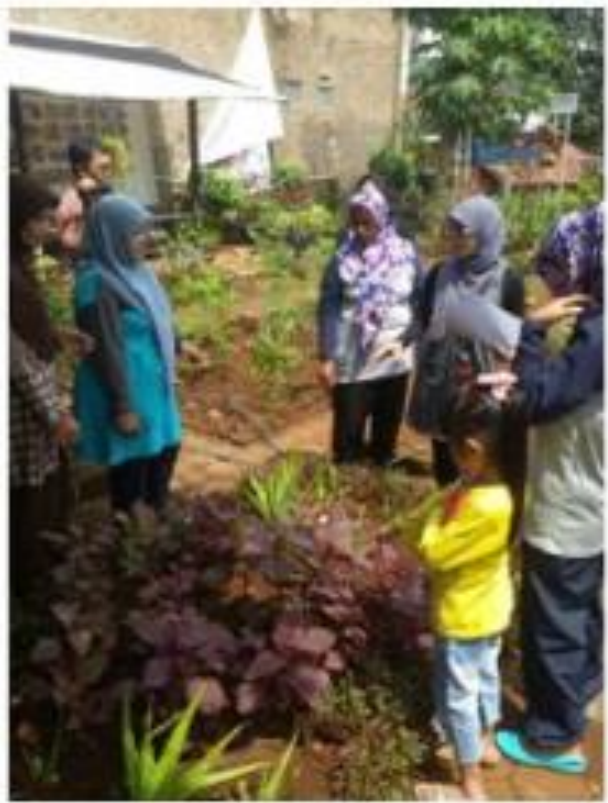

Gambar 3. Kondisi Lahan Awal Kegiatan Budidaya Tanaman Obat dan Kosmetika

Kondisi lahan percontohan pada awalnya menggunakan penanaman langsung dipermukaan tanah, sedangkan setelah pelaksanaan program ini, penanaman dilakukan secara vertikal, menggunakan besi sebagai penyangga dan wadah plastik memanjang untuk media tanam. Implementasi metode ini diharapkan mampu menambah ruang tanam bagi lahan perkarangan penduduk yang sempit.

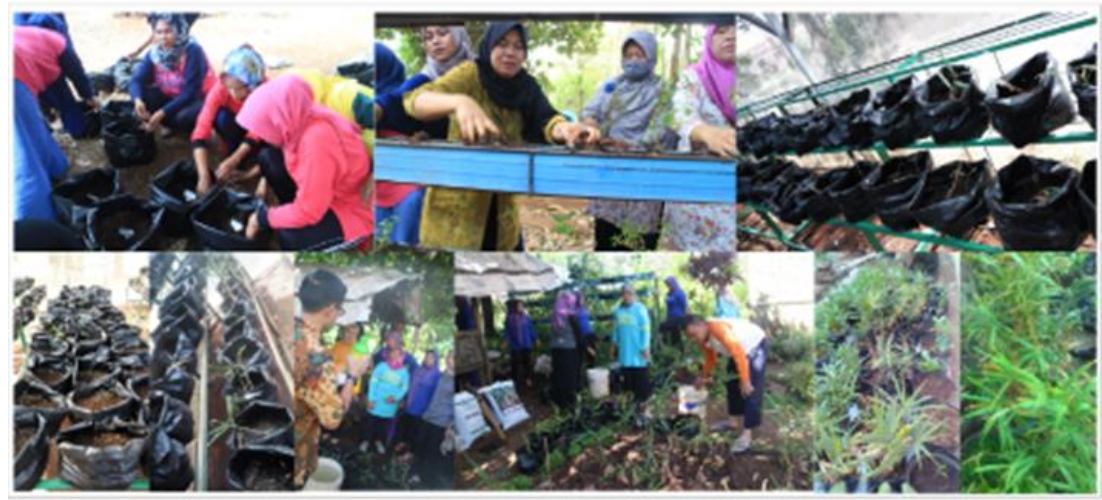

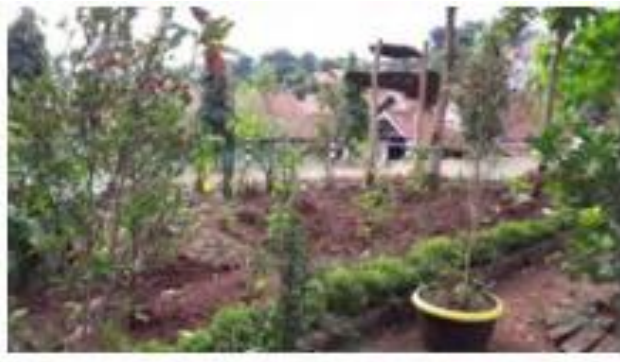

(a)

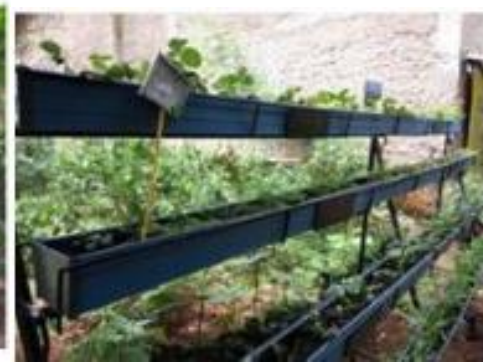

(b)

Gambar 4. Kondisi lahan percontohan tanaman obat dan kosmetika; Sebelum (a) dan Sesudah (b) Pelaksanaan Kegiatan 


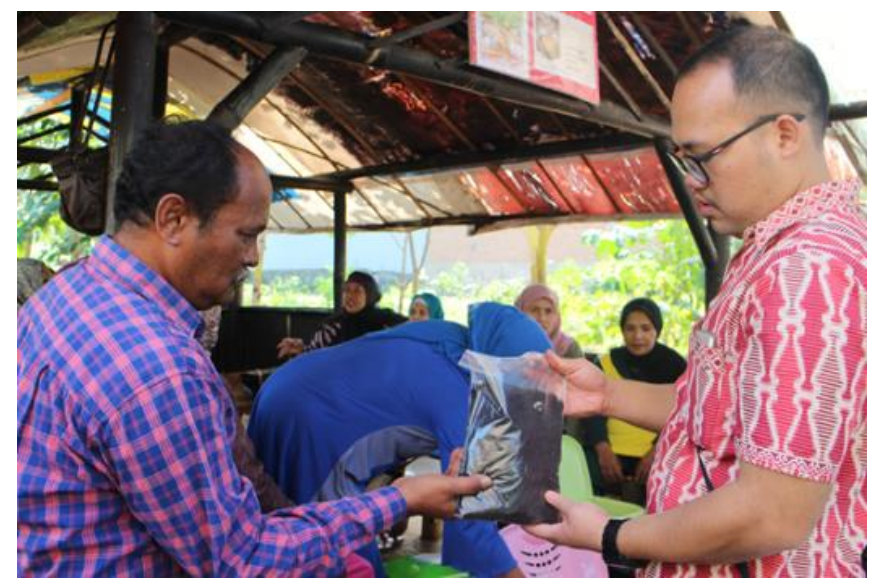

Gambar 5. Contoh Pupuk Kompos Olahan Warga Menggunakan Metode Takakura

\section{SIMPULAN}

Adapun kesimpulan dari kegiatan pemanfaatan perkarangan untuk tanaman obat dan kosmetika menggunakan metode tanam vertikal antara lain: 1) Kegiatan ini meningkatkan pengetahuan kelompok sasaran dalam memanfaatkan halaman rumah sebagai lahan tanaman obat dan kosmetika; 2) Kelompok sasaran mulai mengenal tata cara tanam tanaman dengan metode vertikal; dan 3) Solusi pemanfaatan kompos dari metode Takakura dapat diselesaikan dengan menggunakan tanam vertikal.

\section{REFERENSI}

Azzamy. (2016). Jenis dan contoh tanaman untuk taman vertikal (Vertikal garden). Retrieved August 03, 2018 from https://mitalom.com/jenis-dan-contoh-tanaman-untuk-tamanvertikal-vertikal-garden

Byaz, A. (2013). Vertical garden dan Toga (tanaman obat keluarga) jadi pilihan. Retrieved August 03, 2018 from https://bsdjtv.blogspot.com/2013/11/vertical-garden-dan-togatanaman-obat.html

Halimah, U. (2007). Desa Cibiru Wetan (2006). Retrieved November 11, 2018 from https://uun-halimah.blogspot.com/2007/12/desa-cibiru-wetan-2006.html

Kasim, F., \& Segara, E. A. (2012). Studi kualitatif mengenai faktor-faktor yang mempengaruhi rendahnya penggunaan tanaman obat keluarga di wilayah kerja Puskesmas Cipeuyeum Kecamatan Haurwangi Kabupaten Cianjur. Bandung: Universitas Kristen Maranatha.

Muhsinin, S., Dinata, D. I., Andriansyah, I., \& Asnawi, A. (2019). Peningkatan Potensi Ibu Rumah Tangga dalam Mengolah Sampah Organik Rumah Tangga Menggunakan Metode Takakura di Desa Cibiru Wetan, Kabupaten Bandung. Jurnal Pengabdian Pada Masyarakat, 4(2), 179-186. https://doi.org/10.30653/002.201942.110 
Muttaqin, F. Z., Aligita, W., Muhsinin, S., Juanda, D., \& Asnawi, A. (2018). Desa mitra dalam budidaya tanaman obat keluarga menuju Desa Cibiru Wetan sebagai sentra herbal. Jurnal Pengabdian Pada Masyarakat, 3(2), 159-164. https://doi.org/10.30653/002.201832.59

Rahmansyah. (2017). Jenis tanaman herbal asal indonesia ini berkhasiat untuk kesehatan tubuh. Retrieved August 03, 2018 from https://www.kabarrantau.com/jenis-tanamanherbal-asal-indonesia-ini-berkhasiat-untuk-kesehatan-tubuh

Suwahyono, U. (2011). Petunjuk praktis penggunaan pupuk organik secara efektif dan efisien. Jakarta: Penebar Swadaya.

Utomo, A. S. W. (2007). Pembuatan kompos dengan limbah organik. Jakarta: Sinar Cemerlang Abadi.

Yuliarti, N. (2009). 1001 cara menghasilkan pupuk organik. Yogyakarta: Lyli Publiser. 